\title{
Influence of preparation procedures on the phenolic content, antioxidant and antidiabetic activities of green and black teas
}

\author{
Tânia Santos de Almeida, ${ }^{1,2, *}$ Maria Eduarda Machado Araújo, ${ }^{2}$ Lucía González Rodríguez, ${ }^{2}$ Ana \\ Júlio, ${ }^{1}$ Beatriz Garcia Mendes, ${ }^{3}$ Rui Miguel Borges dos Santos, ${ }^{2,4}$ José Artur Martinho Simões ${ }^{2}$
}

\begin{abstract}
${ }^{1}$ CBIOS - Universidade Lusófona's Research Center for Biosciences and Health Technologies, Lisboa, Portugal, ${ }^{2}$ Centro de Química e Bioquímica, Faculdade de Ciências, Universidade de Lisboa, Lisboa, Portugal, ${ }^{3}$ Centro de Ciências da Saúde, Departamento de Análises Clínicas, Universidade Federal de Santa Catarina, Florianópolis, Brasil, ${ }^{4}$ CBMR - Center for Biomedical Research, Universidade do Algarve, Faro, Portugal
\end{abstract}

\begin{abstract}
The influence of common tea preparation procedures (temperature, infusion time, consumption time interval and tea bag/loose-leaf) and the type of water used, on the total phenolic content (TPC), the radical scavenging activity and the $\alpha$-glucosidase inhibitory activity were assessed. Higher TPC and antioxidant activity were obtained when using lower mineralized waters. Tea bags also evidenced higher antioxidant activity than loose-leaf samples. Under the same conditions $\left(90^{\circ} \mathrm{C}\right.$ and five minutes of infusion time) green tea contains almost twice the quantity of polyphenols and the free radical scavenging ability of black tea. In the $\alpha$-glucosidase assay all infusions were active (97-100 \%). Furthermore, HPLC allowed to identify some of the polyphenols present in both teas and to monitor their composition change with time. After twenty-four hours, the antioxidant activity was maintained without significant changes, but a small decrease in enzyme inhibition was observed, although this activity was still very high.
\end{abstract}

Keywords: Black tea. Green tea. Antioxidant activity. $\alpha$-Glucosidase activity. Water mineralization.

\section{INTRODUCTION}

The health benefits of tea are widely recognized by medical and nutritional experts (Harbowy, Balentine, 1997; Huang, Boxin, Prior, 2005; Komes et al., 2010; Samaniego-Sánchez et al., 2011). Indeed, tea is well known as a nutritional source of bioactive compounds, namely polyphenols that provide antioxidant activity. These chemicals can play an important role in adsorbing and neutralizing free radicals, quenching singlet and triplet oxygen, or decomposing peroxides. They act as radicalscavengers and are able to inhibit lipid peroxidation and other free radical-mediated processes, protecting the human body from several diseases attributed to the reactions of radicals.

Furthermore, different types of teas have been described as potent $\alpha$-glucosidase inhibitors. Inhibition

\footnotetext{
*Correspondence: T. Almeida. Research Center for Biosciences and Health Technologies - CBIOS, Universidade Lusófona's, Campo Grande 376, 1749-024 - Lisboa, Portugal. Phone: 00351217515500 Ext: 629. E-mail: tania.almeida@ulusofona.pt
}

of the $\alpha$-glucosidase enzyme may suppress postprandial hyperglycemia and thus these inhibitors are usually used to prevent or to treat type-2 diabetes (Hosoda et al., 2003).

Nevertheless, the composition of tea infusion strongly depends on a large number of factors, viz. growing conditions (i.e. season, species, age of the leaf, climate, type of soil, and agricultural practices), storage, and also the domestic procedures used to prepare the infusion, such as brewing time (Samaniego-Sánchez et $a l ., 2011)$ and the type of water used. Furthermore, even though the same plant is used (Camellia sinensis) for both green and black teas, black tea is prepared from leaves that have undergone a crushing and fermenting process, while in green tea the leaves are not fermented, they are only withered and steamed.

Being the second most consumed beverage worldwide, it is not surprising that studies on tea antioxidant activities are abundant, especially those related to green tea. Nonetheless, and to the best of our knowledge, most studies do not consider the usual drinking conditions and therefore their usefulness for the consumer is somewhat limited (Carter, 1971; Halliwell, 
Gutteridge, 1989; Benzie, Szeto, 1999; Sharma et al., 2008). The few exceptions that do contemplate some of these brewing conditions (Komes et al., 2010; Samaniego-Sánchez et al., 2011; Sharpe et al., 2016), refer only to green tea (GT) and do not evaluate black tea (BT), nor how the infusions' properties are influenced by the use of different types of water. Thus, since both green and black teas are amongst the most consumed infusions, it is therefore important to assess their beneficial properties in conditions as similar as possible to those chosen by the end user. Moreover, in this work, both studied BT and GT were obtained from the same local farm, thus allowing to confirm that the attained differences in the composition and in the activities, were the result of industrial processing and brewing conditions and not because of environmental differences due to different harvesting locations.

There is some debate about what is the best way to brew each one of the tea selections. The general recommendations try to optimize taste and aroma (Samaniego-Sánchez et al., 2011) but ultimately it ends up being a matter of personal choice. Nonetheless, it is relevant to evaluate the overall conditions that may maximize the beneficial health effects of the infusions and convey that information to the general public.

In the present work, a suitable experimental methodology was applied to evaluate the total phenolic content (TPC), the antioxidant activity (radical scavenging activity, RSA), and hypoglycemic properties (inhibition of $\alpha$-glucosidase) of black and green Azorean organic teas prepared under different conditions and also with several mineral and tap water samples. Green and black (orange pekoe) teas were obtained from the same producer (Gorreana, 2015), which may be relevant for a true comparison amongst both type of teas. Gorreana tea is produced in São Miguel, Azores (Portugal), and it is claimed to be an organic product, recognized for its very high quality.

\section{MATERIAL AND METHODS}

\section{Chemicals}

Folin-Ciocalteu and sodium carbonate were of analytical grade and supplied by Aldrich (Zagreb, Croatia). Ethanol (PA grade) was purchased from Panreac (Deventer, Netherlands). DPPH (2,2-diphenyl-1picrylhydrazyl), $\alpha$-glucosidase recombinant (EC 3.2.1.20) from Saccharomyces cerevisiae, and p-nitrophenyl- $\alpha-\mathrm{D}-$ glucopyranoside (PNPG) were purchased from Sigma (Buchs, Switzerland).

\section{Instrumentation}

Spectrophotometric measurements were made using a Shimadzu UV 1603-Visible Spectrometer. Micropipettes (VWR, Poland) were used for volume measurements. To heat and monitor the water temperature, a heating plate with an electronic contact thermometer $\left(\mathrm{IKA}^{\circledR} \mathrm{RCT}\right.$ classic, VWR, Germany) was used. Conductimetric measurements were determined with a Metrohm 644 conductivity meter. The HPLC analysis was carried out in a Liquid Chromatograph Finnigan TM Surveyor Plus Modular LC System, equipped with a diode array detector and a Lychromasphere $5 \mu \mathrm{m} \mathrm{C}_{18}$ column (Merck, Germany) and Xcalibur software.

\section{Infusion preparation}

The Gorreana green (GT) and black pekoe (BT) teas were purchased in a tea shop. Infusions were prepared considering the general recommendations of tea connoisseurs to obtain the best flavour and aroma: $2 \mathrm{~g}$ (a rounded teaspoon) of tea per cup (Emsley, 2003). To mimic domestic brewing procedures, the infusions were prepared using aqueous extraction in a ceramic teapot. Two grams of tea per $250 \mathrm{~mL}$ of water were used. General recommendations to obtain the best taste and aroma suggest that GT should be prepared at $80^{\circ} \mathrm{C}$ with a 3-minute infusion and BT should be prepared at $90{ }^{\circ} \mathrm{C}$ with a 5-minute infusion.

For each assay, freshly prepared infusions of the dry loose-leaves or tea bags were brewed according to the following protocol: distilled water was heated $\left(70^{\circ} \mathrm{C}\right.$, $80^{\circ} \mathrm{C}, 90^{\circ} \mathrm{C}$ or $100^{\circ} \mathrm{C}$ ) and added over the tea leaves (or bags) in a clean ceramic tea pot $(2 \mathrm{~g}$ tea $/ 250 \mathrm{~mL}$ water $)$. After infusion time (three minutes for GT and five minutes for BT), the solutions were slowly stirred with a glass rod (ten consecutive one-second circular movements) and filtered, using a strainer to remove the large leaves and a filter paper to ensure that all small particles were equally retained. After filtration, the samples were once again stirred with a glass rod, using the same procedure. For the assessment of the antioxidant activity, each tea infusion was prepared tree times and five replicates were used in each independent experiment. To assess the $\alpha$-glucosidase inhibitory activity three replicates were used.

\section{Influence of water mineralization}

To evaluate the effect of water mineralization on the antioxidant properties of a cup of tea, six different water samples were used. Besides distilled laboratory 
water, two mineral water samples were used: MW1 (total mineralization referenced in the bottle: $45 \mathrm{mg} / \mathrm{L}$; Hardness: $4 \mathrm{mg} / \mathrm{L}$; Calcium: $0.8 \mathrm{mg} / \mathrm{L}$; Bicarbonate: $5.1 \mathrm{mg} / \mathrm{L}$ ) and MW2 (total mineralization referenced in the bottle: $309 \mathrm{mg} / \mathrm{L}$; Hardness: $291 \mathrm{mg} / \mathrm{L}$; Calcium: $78 \mathrm{mg} / \mathrm{L}$; Bicarbonate: $357 \mathrm{mg} / \mathrm{L}$ ), both purchased in a local supermarket. Teas were also prepared with two different tap water samples (TW1 and TW2), obtained from two different locations in Lisbon, and with a water sample collected from a well (WW) belonging to a private farm, located $20 \mathrm{~km}$ north of Lisbon. For all assays, blanks were prepared with the same water sample used to prepare the infusion and heated at the same temperature.

\section{Total phenolic content assay}

The samples were analysed using the Folin-Ciocalteu reagent (Singleton, Orthofer, Lamuela-Raventos, 1998). The procedure used in the present study was described before (Mata et al., 2007). Briefly, an aliquot $(50 \mu \mathrm{L})$ of the recently prepared tea was diluted with $2.25 \mathrm{~mL}$ of distilled water. Then, $50 \mu \mathrm{L}$ of the Folin-Ciocalteu reagent was added. The mixture was shaken and allowed to stand for three minutes before addition of $150 \mu \mathrm{L}$ of a $2 \%$ aqueous solution of $\mathrm{Na}_{2} \mathrm{CO}_{3}$. After incubation in the dark for two hours in a stoppered vial, the absorbance at $760 \mathrm{~nm}$ was read versus a blank containing the water sample used to prepare tea. This procedure was repeated five times for each tea sample. The results were expressed in milligrams of gallic acid (used as standard) per gram of tea. A $0.5 \mathrm{~g} / \mathrm{L}$ stock solution and distilled water were used to prepare a dilution series in order to obtain the calibration curve:

$$
A=0.7802 \times[\text { gallic acid }]-0.0056\left(\mathrm{r}^{2}=0.9927\right)
$$

where $A$ is the absorbance and [gallic acid] is the concentration of gallic acid in $\mathrm{mg} \cdot \mathrm{mL}^{-1}$. Data of the TPC were expressed as the average of at least five independent measurements.

\section{Radical scavenging assay with DPPH radical (DPPH assay)}

The assay was performed according to the method reported by Brand-Williams, Cuvelier, and Berset (BrandWilliams, Cuvelier, Berset, 1995), which is based on the reduction of DPPH (2,2-diphenyl-1-picrylhydrazyl) radical in alcoholic solution, in the presence of a hydrogendonating antioxidant, due to the formation of a non-radical form, DPPH-H. The absorbance decrease was followed spectrophotometrically at $517 \mathrm{~nm}$ and a steady state was reached after 30 minutes. The procedure used in the present study was also described before (Mata et al., 2007). Briefly, an aliquot $(25 \mu \mathrm{L})$ of the recently prepared tea was placed in a stoppered small flask and $2.5 \mathrm{~mL}$ of freshly prepared $0.004 \%$ ethanolic solution of DPPH radical was added. The mixture was shaken and maintained at room temperature, in the dark, for 30 minutes. Controls were prepared at the same temperature and with the same water used to prepare the infusions. This procedure was repeated five times for each tea sample. The radical scavenging activities (RSA) of the test samples were expressed as the percentage inhibition of the DPPH radical and calculated according to the following formula:

$$
\operatorname{RSA}(\%)=\left[\left(A_{\mathrm{B}}-A_{\mathrm{T}}\right) / A_{\mathrm{B}}\right] \times 100
$$

$A_{\mathrm{B}}$ and $A_{\mathrm{T}}$ are the absorbance values of the blank and the test samples, respectively. RSA data were expressed as the average of at least five independent measurements.

\section{HPLC analysis}

The infusions were analysed by HPLC, injecting $25 \mu \mathrm{L}$ and using a gradient composed of solution $\mathrm{A}$ (acetonitrile) and solution B (water with $0.2 \%$ phosphoric acid) as follows:

$\mathrm{t}=0$ min: eluent $\mathrm{A}(10 \%)$, eluent $\mathrm{B}(90 \%)$

$\mathrm{t}=5$ min: eluent $\mathrm{A}(10 \%)$, eluent $\mathrm{B}(90 \%)$

$t=20$ min: eluent $A(20 \%)$, eluent $B(80 \%)$

$\mathrm{t}=25$ min: eluent $\mathrm{A}(20 \%)$, eluent B (80\%)

Gallic acid, catechin, epigallocatechin, epicatechin, and caffeine were run under the same conditions, using 0.1 $\mathrm{mg} / \mathrm{mL}$ solutions in methanol. The detection was carried at $280 \mathrm{~nm}$ acording to Gao et al. (2008). The chromatograms were obtained by using a Photodiode Array Detector.

\section{$\alpha$-Glucosidase inhibitory activity}

The $\alpha$-glucosidase inhibitory activity was assessed by modification of a previously reported procedure (Queiroz et al., 2013). Briefly, $60 \mu \mathrm{L}$ of the recently prepared tea was incubated with $270 \mu \mathrm{L}$ of the $\alpha$-glucosidase enzyme $(0.2 \mathrm{U} / \mathrm{mL})$ in potassium phosphate buffer $(10$ $\mathrm{mM}, \mathrm{pH} 6.9$ ) for 5 minutes, at $37^{\circ} \mathrm{C}$. Then, $150 \mu \mathrm{L}$ of the enzyme substrate PNPG (p-nitrophenyl- $\alpha$-Dglucopyranoside) $(5 \mathrm{mM})$ and $420 \mu \mathrm{L}$ of the phosphate buffer were added, and the samples were incubated at $37^{\circ} \mathrm{C}$ for 30 minutes. After incubation the reaction was stopped by adding $900 \mu \mathrm{L}$ of sodium carbonate $(1.0 \mathrm{M})$. The absorbance of 4-nitrophenol, released from PNPG 
by the enzyme, was measured at $405 \mathrm{~nm}$ (Abs sample). The absorbance of a control mixture and that of a blank were also measured (Abs control and Abs background, respectively). Abs control is the absorbance of a mixture that contains $60 \mu \mathrm{L}$ of the phosphate buffer instead of tea sample and all the other reagents; Abs background is the absorbance of a mixture that contains $270 \mu \mathrm{L}$ of the phosphate buffer instead of the enzyme plus the other reagents. Tests were performed in triplicate and inhibition of the enzyme was calculated as follows:

$$
\text { Inhibition }(\%)=\frac{\left[A b s_{\text {control }}-\left(A b s_{\text {sample }}-A b s_{\text {background }}\right)\right]}{A b s_{\text {control }}} \times 100
$$

\section{Statistical analysis}

Differences in mean values of the results were evaluated by one-way analysis of variance (ANOVA) followed by Tukey's multiple comparison test. Values were expressed as mean \pm standard deviation (SD). The differences between individual means were considered to be significant with at least $\mathrm{p}<0.05$.

\section{RESULTS AND DISCUSSION}

In this work black and green tea produced in an organic farm (Gorreana, Azores) were investigated. Furthermore, it is interesting to note that Azores is the only European region where Camellia sinensis is cultivated for commercial purposes. Some work on Gorreana tea extracts has already been reported before (Baptista, Tavares, Carvalho, 1998; Baptista, Taveres, Carvalho, 1999). Nonetheless, the methodologies used in these studies did not reflect the way tea is commonly prepared.

First and foremost, it should be recalled that in this work the tea preparation protocol was optimized to guarantee reproducibility, which is crucial for the reliability of the overall results. To achieve this, after pouring the water onto the leaves, it was always ensured that all leaves were submersed. Subsequently, it was also important to use, as much as possible, a similar stirring for all samples. Also, the performed preparation procedure, described above, tried to mimic the common tea spoon stirring procedure.

Filtration with filter paper was also critical, especially for the green tea, since its leaves are small and brittle. The residues remaining in the infusion would cause additional extraction, yielding irreproducible results. Hence, and although the domestic practice does not include this procedure, the filtration was essential to guarantee reproducible data.
According to tea appraisers to obtain a pleasant beverage, with the exact astringency, green tea should be prepared at $80^{\circ} \mathrm{C}$ and infused for about 3 minutes, whereas black tea should be prepared at $90^{\circ} \mathrm{C}$ and infused for around 5 minutes. Therefore, these were the infusion periods used to study the influence of temperature on RSA, TPC, and the $\alpha$-glucosidase inhibition. Nevertheless, for comparative purposes, green tea was also prepared at $90^{\circ} \mathrm{C}$ and a 5-minute infusion.

\section{Influence of water temperature on the TPC and the RSA}

Both BT and GT were prepared at four temperatures $\left(70{ }^{\circ} \mathrm{C}, 80^{\circ} \mathrm{C}, 90^{\circ} \mathrm{C}\right.$, and $\left.100^{\circ} \mathrm{C}\right)$. The TPC and the RSA were determined at each temperature and the results are collected in Table I.

As expected for both teas, the higher the infusion temperature the higher the RSA and the TPC values.

In general, results showed that, when compared to BT, GT presented higher TPC and RSA values. Additionally, the comparison between the values obtained for GT and BT, prepared at the same temperature and infusion time $\left(90^{\circ} \mathrm{C}, 5\right.$ minutes $)$, revealed a significant difference $(\mathrm{p}<0.001)$ between the two teas, where the value obtained for GT is twice the value found for BT (Table I).

Moreover, for GT results from both assays, obtained at different temperatures, show that the lowest TPC and RSA values were obtained at $70{ }^{\circ} \mathrm{C}$. The same tendency is observed for BT, although in this case, no significant differences were observed between infusions prepared at $70^{\circ} \mathrm{C}$ and $80^{\circ} \mathrm{C}$. Only BT infusions prepared at $90^{\circ} \mathrm{C}$ and $100{ }^{\circ} \mathrm{C}$ show higher values, with statistically significant differences $(\mathrm{p}<0.001)$, when compared to the results obtained at $70^{\circ} \mathrm{C}$ and $80^{\circ} \mathrm{C}$. Hence, for BT an increase in temperature from $80^{\circ} \mathrm{C}$ to $90^{\circ} \mathrm{C}$ was more significant ( $\mathrm{p}<0.001$ ) than from $70^{\circ} \mathrm{C}$ to $80^{\circ} \mathrm{C}$. On the other hand, RSA values for GT, show that an increase in temperature from $70^{\circ} \mathrm{C}$ to $80^{\circ} \mathrm{C}$ is more significant $(\mathrm{p}<0.001)$ than from $80{ }^{\circ} \mathrm{C}$ to $90^{\circ} \mathrm{C}$ or from $90^{\circ} \mathrm{C}$ to $100{ }^{\circ} \mathrm{C}$, where no significant differences were observed amongst them. From these results it may be inferred that the majority of the polyphenols present in the GT were extracted at $80^{\circ} \mathrm{C}$. While for BT the higher temperatures have a greater impact on the resulting antioxidant activity. Hence, these results are in keeping with the current recommendations for the use of water at $80^{\circ} \mathrm{C}$, for the preparation of GT, and at $90^{\circ} \mathrm{C}$, for the preparation of BT. The present results confirm that these temperatures, which are considered appropriate to achieve the best flavour and aroma, also 
allow to obtain very good antioxidant properties in each brew.

Moreover, the obtained data also showed that RSA increases with increasing TPC, with a good correlation being observed for both green and black teas.

The composition of each brew prepared at different temperatures was also investigated by HPLC (data not shown). Five compounds that have been previously found in tea, namely gallic acid, catechin, epigallocatechin, epicatechin, and caffeine, were used as standards, run under the same conditions and identified in tea chromatograms. As expected, the obtained HPLC chromatograms are similar, mostly differing in the peak intensities. This indicates that temperature only promotes a better dissolution of the components and also that no new relevant components were extracted at higher temperatures.

\section{Influence of type of infusion (loose-leaf vs. tea bags)}

Since commercial tea bags are widely used in restaurants and coffee shops, the antioxidant activity of black and green tea bags, sold by the same trade company, was also evaluated (Table I). When comparing tea bags with loose-leaf infusions, in general the TPC and RSA for both GT and BT bags, showed higher values than those obtained for the loose-leaf infusions, prepared at the same temperature and infusion time conditions. A larger surface area of the tea fannings in the tea bags, allowing a better extraction of the polyphenols and yielding a higher RSA, may justify the differences.

Although a higher RSA can be regarded as a positive feature, it can be argued that the larger surface area will also promote the evaporation of other substances that are relevant for the tea flavour and aroma.

\section{Influence of the tea consumption period}

It is widely recommended that tea should be enjoyed when freshly prepared. However, many consumers like drinking tea over time, as it represents a non-caloric alternative to simple water. Thus, it is relevant to investigate if the antioxidant properties of tea infusions change with time.

The RSA and TPC of freshly prepared cups of green and black teas were evaluated, and their changes were monitored over a 24 -hour period $(\mathrm{t}=0 \mathrm{~min}, \mathrm{t}=40 \mathrm{~min}, \mathrm{t}$ $=80 \min , \mathrm{t}=120 \min , \mathrm{t}=160 \mathrm{~min}, \mathrm{t}=200 \mathrm{~min}$, and $\mathrm{t}=$ $24 \mathrm{~h}$ ). The results are presented in Table II. Both GT and BT show a small decrease in RSA values in the first 40 minutes, with statistically significant differences. After that time the RSA values seem to stabilize over time. For TPC, no significant differences were found during the studied period.

TABLE I - Effect of the infusion temperature and time on the total phenolic content (TPC) and radical scavenging activity (RSA) of green and black teas

\begin{tabular}{|c|c|c|c|c|c|}
\hline Tea & & $\begin{array}{c}\text { Infusion } \\
\text { temperature }\left({ }^{\circ} \mathrm{C}\right)\end{array}$ & Infusion time (min) & $\begin{array}{c}\text { TPC } \\
(\mathrm{GAE}, \mathrm{mg} / \mathrm{mL})\end{array}$ & RSA (\%) \\
\hline \multirow{9}{*}{ Leaves } & \multirow{5}{*}{ Green } & 70 & 3 & $0.26 \pm 0.01^{\mathrm{a}}$ & $30.0 \pm 2.8^{\mathrm{a}}$ \\
\hline & & 80 & 3 & $0.30 \pm 0.00^{\mathrm{b}}$ & $38.9 \pm 2.6^{b}$ \\
\hline & & 90 & 3 & $0.32 \pm 0.01^{b}$ & $41.7 \pm 2.2^{\mathrm{b}}$ \\
\hline & & 90 & 5 & $0.37 \pm 0.02^{\mathrm{c}}$ & $42.4 \pm 2.6^{b}$ \\
\hline & & 100 & 3 & $0.33 \pm 0.01^{\mathrm{d}}$ & $41.8 \pm 2.1^{\mathrm{b}}$ \\
\hline & \multirow{4}{*}{ Black } & 70 & 5 & $0.14 \pm 0.01^{\mathrm{e}}$ & $14.8 \pm 1.6^{\mathrm{c}}$ \\
\hline & & 80 & 5 & $0.15 \pm 0.00^{\mathrm{e}}$ & $17.2 \pm 1.4^{\mathrm{c}}$ \\
\hline & & 90 & 5 & $0.19 \pm 0.00^{\mathrm{f}}$ & $20.7 \pm 1.5^{\mathrm{d}}$ \\
\hline & & 100 & 5 & $0.20 \pm 0.01^{\mathrm{g}}$ & $25.3 \pm 2.7^{\mathrm{e}}$ \\
\hline \multirow{3}{*}{ Bags } & \multirow{2}{*}{ Green } & 80 & 3 & $0.52 \pm 0.02^{\mathrm{h}}$ & $41.5 \pm 3.2^{b}$ \\
\hline & & 90 & 5 & $0.64 \pm 0.02^{\mathrm{i}}$ & $70.3 \pm 3.4^{f}$ \\
\hline & $\overline{\text { Black }}$ & 90 & 5 & $0.50 \pm 0.02^{\mathrm{h}}$ & $36.0 \pm 2.0^{b}$ \\
\hline
\end{tabular}

Each uncertainty represents the standard deviation of the mean of three experiments (each with five replicates), mean \pm SD. Different letters in the each column (TPC or RSA) are indicative of significant statistical differences between the values with at least $\mathrm{p}<0.05$ (ANOVA, Tukey's test). GAE: Data expressed as gallic acid equivalents. RSA: expressed as percentage inhibition of the DPPH radical. 
The chemical composition of tea is well studied and includes many compounds, not only polyphenols but also some terpenes that confer its characteristic aroma (Caralambous, Inglett, 1978; Harbowy, Balentine, 1997). The antioxidant properties of many terpenes have already been evaluated (Ruberto, Barata, 2000) including some of those that are accountable for the tea aroma, like geraniol, linalool or octanal. Since these compounds represent some of the tea volatiles and, according to some authors (Choi et al., 2000), they have good or moderate RSA in the DPPH assay, the small initial decrease in the antioxidant activity may be due to the loss of active volatiles in the first minutes after tea preparation. The fact that HPLC profile of green and black teas do not change with time (Figure 1), just indicates that the phenolic content (non-volatile) does not change with infusion time.

\section{Influence of water mineralization on the antioxidant properties}

It has been mentioned that, when preparing tea, one should avoid using hard water. This type of water will damage the organoleptic properties of the infusion, since the minerals in water cause unpleasant tea scum and a bitter taste (Emsley, 2003). But how does the water mineralization affect the antioxidant properties of a freshly prepared cup of tea?

Six different water samples were used in our experiments: distilled water (DW), two commercial mineral water samples (MW1 and MW2), two tap water samples (TW1 and TW2) from different locations in Lisbon, and a water sample from a private well (WW), also from the Lisbon district. The water mineralization was gauged by its electrical conductivity (in ascending order, DW: $1.053 \mu \mathrm{S} / \mathrm{cm}$; MW1: $41.31 \mu \mathrm{S} / \mathrm{cm}$; TW1: $162.0 \mu \mathrm{S} / \mathrm{cm}$; TW2: $307.8 \mu \mathrm{S} / \mathrm{cm}$; MW2: $534.6 \mu \mathrm{S} / \mathrm{cm}$; WW: $931.5 \mu \mathrm{S} / \mathrm{cm})$.

The results for the TPC of black and green teas, prepared with the six water samples, are presented in Table III and Figures 2 and 3.

As expected, TPC and RSA are once again considerably higher in GT than in BT for all the water samples used. TPC results are less sensitive than RSA to the water mineral content. Nonetheless, TPC results still show that for both GT and BT, the more mineralized waters WW and MW2 present lower TPC values when compared to DW and MW1, and these differences are statistically significant $(\mathrm{p}<0.001)$. For GT, WW and MW2 also present lower TPC values compared to TW1 $(\mathrm{p}<0.01)$.

The results for the RSA (Table III) parallel those for the TPC, but they are amplified. In this case, RSA values for infusions prepared with TW1, TW2, MW2 and WW are all smaller and statistically different $(\mathrm{p}<0.001)$ from those attained with the DW and MW1, for both GT and BT. Hence, the infusions with higher antioxidant activity are those prepared with the lower mineralized commercial water (MW1) and DW.

In summary, water mineralization, as measured by the water conductivity, has a clear influence on the TPC and RSA in both black and green tea infusions. Results show that the higher the water conductivity the lower TPC or RSA values attained. It is known that the higher the water mineralization, the lower the extraction of organic matter (Mossion et al. 2008), which should translate in lower TPC and RSA values, as found in this study. Furthermore, highly mineralized waters have higher contents in calcium, which may be complexed with pectins in cell walls (Mossion et al., 2008) and also explain

TABLE II - Total phenolic content (TPC) and radical scavenging activity (RSA) of green and black tea infusions with time

\begin{tabular}{lccccc}
\hline \multirow{2}{*}{ Time (min) } & \multicolumn{2}{c}{ Green tea } & & \multicolumn{2}{c}{ Black tea } \\
\cline { 2 - 3 } \cline { 5 - 6 } & TPC (GAE, $\mathbf{~ m}$ / $\mathbf{m L})$ & RSA $(\%)$ & & TPC $($ GAE, $\mathbf{~ m g} / \mathbf{m L})$ & RSA (\%) \\
\hline 0 & $0.37 \pm 0.05$ & $30.4 \pm 4.3^{\mathrm{a}}$ & & $0.16 \pm 0.01$ & $19.7 \pm 1.1^{\mathrm{a}}$ \\
40 & $0.35 \pm 0.00$ & $25.0 \pm 1.0^{\mathrm{b}}$ & & $0.15 \pm 0.01$ & $16.3 \pm 0.3^{\mathrm{b}}$ \\
80 & $0.36 \pm 0.01$ & $25.1 \pm 1.1^{\mathrm{b}}$ & & $0.15 \pm 0.01$ & $15.1 \pm 0.4^{\mathrm{b}}$ \\
120 & $0.36 \pm 0.03$ & $25.5 \pm 0.7^{\mathrm{b}}$ & & $0.15 \pm 0.01$ & $15.4 \pm 0.6^{\mathrm{b}}$ \\
160 & $0.35 \pm 0.01$ & $25.4 \pm 0.6^{\mathrm{b}}$ & & $0.15 \pm 0.01$ & $15.1 \pm 0.4^{\mathrm{b}}$ \\
200 & $0.38 \pm 0.03$ & $26.1 \pm 0.7^{\mathrm{b}}$ & & $0.14 \pm 0.01$ & $15.7 \pm 0.3^{\mathrm{b}}$ \\
24 hours & $0.34 \pm 0.02$ & $26.9 \pm 1.8^{\mathrm{b}}$ & & $0.15 \pm 0.01$ & $15.7 \pm 0.1^{\mathrm{b}}$ \\
\hline
\end{tabular}

Each uncertainty represents the standard deviation of the mean of three experiments (each with five replicates), mean \pm SD. No significant statistical differences $(\mathrm{p}>0.05)$ were found between the TPC values, for each tea. Different letters for RSA column are indicative of significant statistical differences between the values with at least $\mathrm{p}<0.05$ (ANOVA, Tukey's test). GAE: Data expressed as gallic acid equivalents. RSA: Data expressed as percentage inhibition of the DPPH radical. 

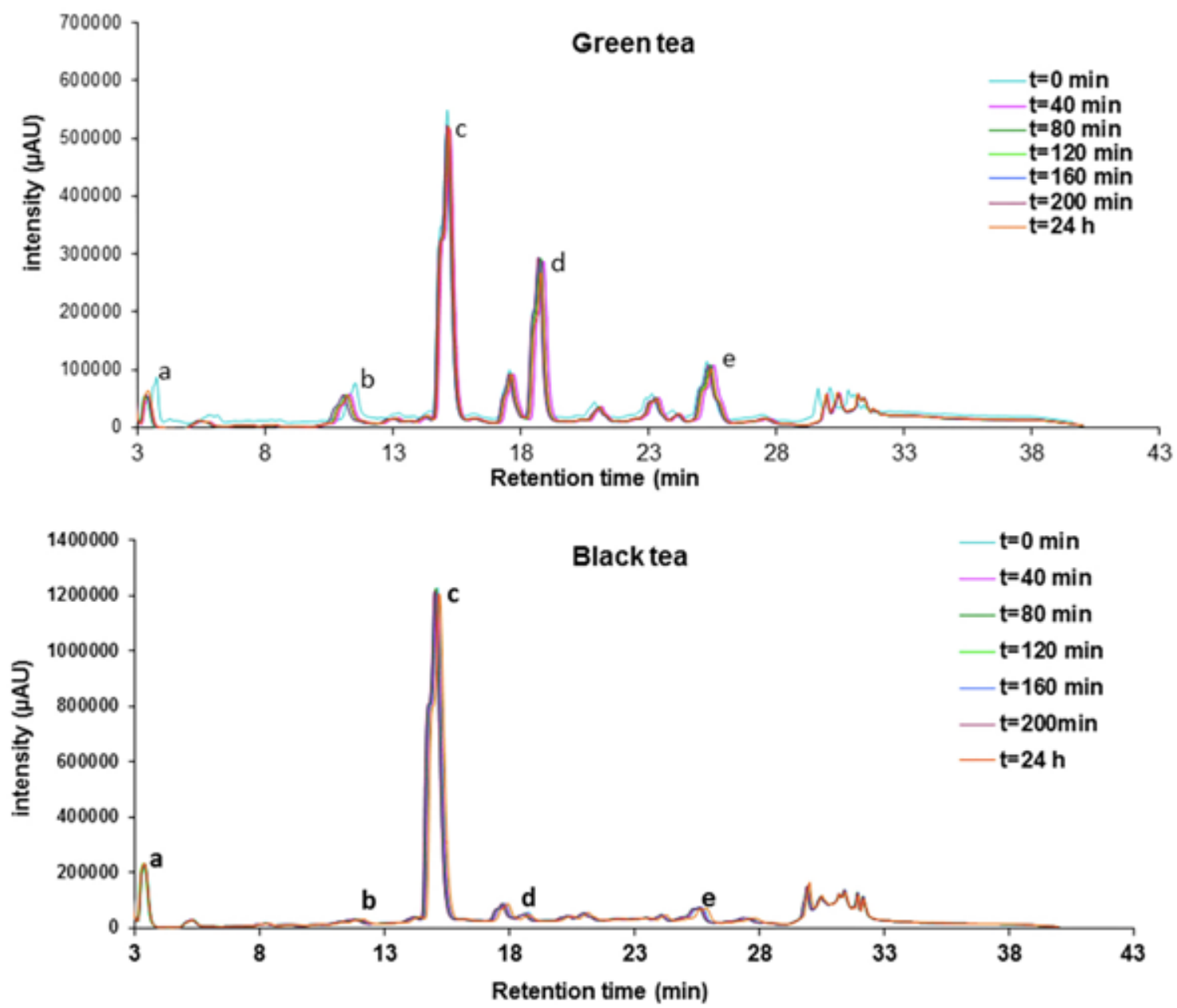

FIGURE 1 - HPLC chromatograms of green and black tea samples over a 24 -hour period. $(\mathbf{a}=$ gallic acid; $\mathbf{b}=$ catechin; $\mathbf{c}=$ caffeine; $\mathbf{d}=$ epigallocatechin; $\mathbf{e}=$ epicatechin)

TABLE III - Total phenolic content (TPC) and radical scavenging activity (RSA) of green and black tea, prepared with different water samples

\begin{tabular}{|c|c|c|c|c|c|}
\hline \multirow{2}{*}{ Water } & \multirow{2}{*}{$\begin{array}{l}\text { Conductivity } \\
(\mu \mathrm{S} / \mathrm{cm})\end{array}$} & \multicolumn{2}{|c|}{ Green tea } & \multicolumn{2}{|c|}{ Black tea } \\
\hline & & TPC (GAE, $\mathrm{mg} / \mathrm{mL})$ & RSA (\%) & TPC (GAE, mg/mL) & RSA (\%) \\
\hline WW & 931.5 & $0.29 \pm 0.00^{\mathrm{a}}$ & $30.7 \pm 0.8^{\mathrm{a}}$ & $0.16 \pm 0.00^{\mathrm{c}}$ & $10.7 \pm 0.1^{\mathrm{f}}$ \\
\hline MW2 & 534.6 & $0.29 \pm 0.01^{\mathrm{a}}$ & $32.4 \pm 0.4^{\mathrm{a}}$ & $0.17 \pm 0.00^{\mathrm{c}}$ & $13.7 \pm 0.3^{\mathrm{g}}$ \\
\hline TW2 & 307.8 & $0.30 \pm 0.00^{\mathrm{a}}$ & $34.8 \pm 0.8^{\mathrm{b}}$ & $0.18 \pm 0.01^{\mathrm{c}}$ & $15.6 \pm 0.3^{\mathrm{h}}$ \\
\hline TW1 & 162.0 & $0.32 \pm 0.00^{\mathrm{b}}$ & $37.0 \pm 0.4^{\mathrm{c}}$ & $0.17 \pm 0.00^{\mathrm{c}}$ & $16.5 \pm 0.1^{\mathrm{h}}$ \\
\hline MW1 & 41.31 & $0.32 \pm 0.00^{\mathrm{b}}$ & $39.6 \pm 1.1^{\mathrm{d}}$ & $0.19 \pm 0.01^{\mathrm{d}}$ & $17.9 \pm 0.2^{\mathrm{i}}$ \\
\hline DW & 1.053 & $0.33 \pm 0.01^{\mathrm{b}}$ & $40.2 \pm 0.3^{\mathrm{e}}$ & $0.19 \pm 0.00^{\mathrm{d}}$ & $19.7 \pm 0.2^{\mathrm{j}}$ \\
\hline
\end{tabular}

Each uncertainty represents the standard deviation of the mean of three experiments (each with five replicates), mean $\pm \mathrm{SD}$. Different letters for each assay (TPC or RSA) are indicative of significant statistical differences between the values with at least $\mathrm{p}<0.05$ (ANOVA, Tukey's test). GAE: Data expressed as gallic acid equivalents. RSA: Data expressed as percentage inhibition of the DPPH radical.

the decrease in tea extraction. Thus, when considering which type of water must be used to prepare tea, the less mineralized waters should be preferred, since they allow a higher extraction of organic compounds and consequently higher antioxidant properties, which may provide health benefits. 


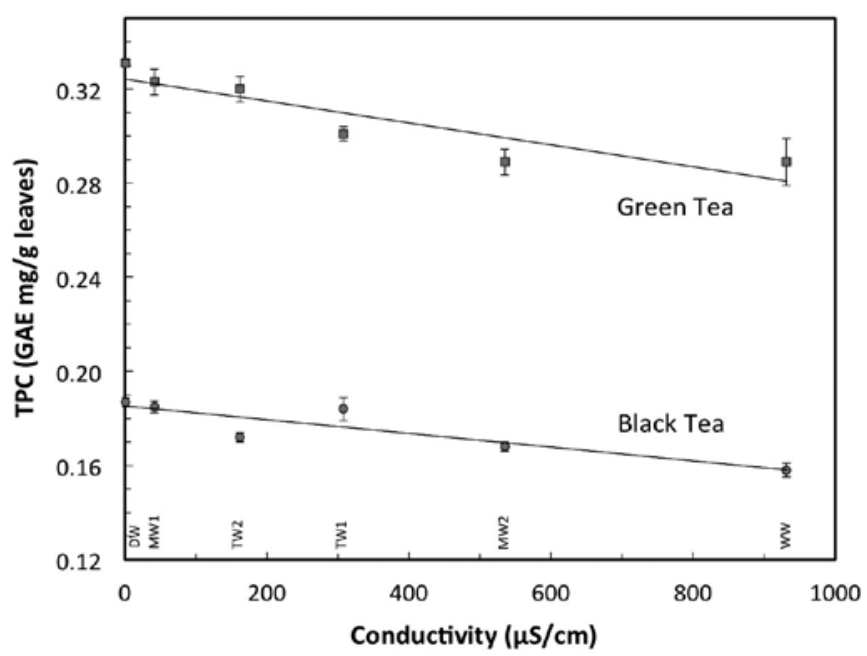

FIGURE 2 - Influence of water conductivity $(\mu \mathrm{S} / \mathrm{cm})$ on the total phenolic content (TPC), relative to TPC of gallic acid (GAE gallic acid equivalent).

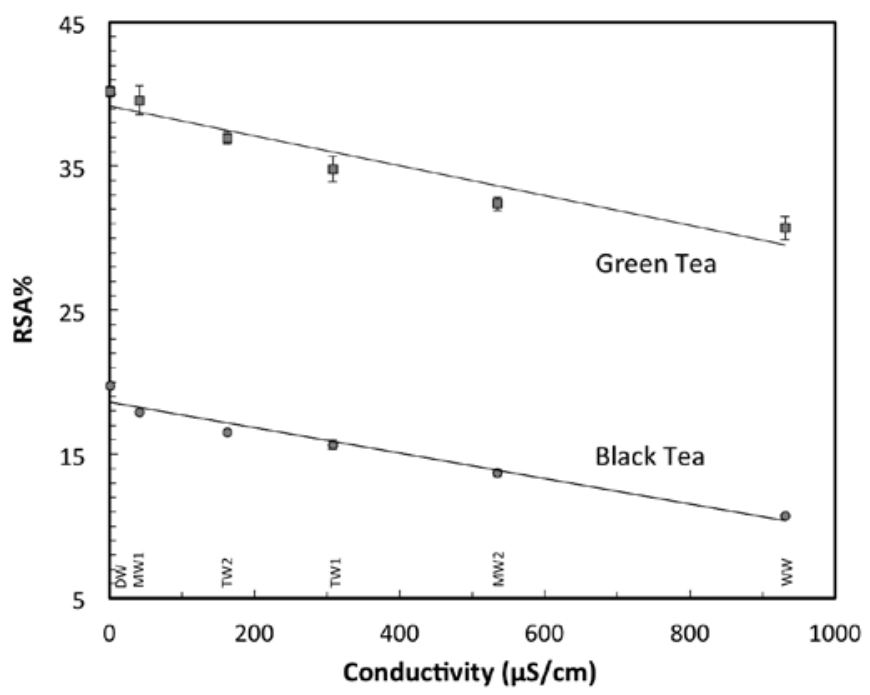

FIGURE 3 - Influence of water conductivity $(\mu \mathrm{S} / \mathrm{cm})$ on the radical scavenging activity (RSA\%).

\section{Inhibition of the $\alpha$-glucosidase enzyme}

Type-2 diabetes mellitus, characterized by high blood sugar and metabolic disorder, is an emerging health problem in Western societies. $\alpha$-Glucosidase is an enzyme that plays an important role in the regulation of postprandial blood glucose levels in the human body, by the breakdown of $\alpha$-glucosidic bonds (Li, Qian, Li, 2010). Its inhibitors can suppress postprandial hyperglycemia and are commonly used to prevent or treat type- 2 diabetes.

Based on ethnomedicinal claims and epidemiological, experimental, and clinical evidences, tea from Camellia sinensis may have hypoglycaemic, antihyperglycaemic, and antidiabetic effects (MacKenzie, Leary, Brooks, 2007; Abeywickrama, Ratnasooriya, Amarakoon, 2011; Park et al., 2014). In vitro studies suggest that catechins and theaflavins help to prevent hyperglycemia by enhancing insulin activity and possibly by preventing damage to $\beta$-cells (Anderson, Polansky, 2002). Additionally, different types of tea and its compounds are potent $\alpha$-glucosidase and $\alpha$-amylase inhibitors (Koh et al., 2010; Li, Qian, Li, 2010). A prospective epidemiological study done in Japan found that Japanese who drink six or more cups of green tea per day have a $33 \%$ lower risk of developing type 2 diabetes mellitus compared to those who drink one (or less) cup per day (Iso et al., 2016). In adults with type-2 diabetes, fasting blood glucose dropped considerably after the intake of 1.5 L of oolong tea/day, during a four-week period (Hosoda $e t$ al., 2003). On the other hand, researchers in the USA found that when using capsules containing standardized extract of green and black tea, no hypoglycemic effect was observed in adults with type 2 diabetes mellitus, over a 3-month period (MacKenzie, Leary, Brooks, 2007).

Nonetheless, to the best of our knowledge, there are no studies on the hypoglycemic activity of infusions prepared with green and black teas in conditions similar to those used at home. In this study, the effect of GT and BT on $\alpha$-glucosidase was investigated immediately after preparation $(\mathrm{t}=0)$ and after a $24 \mathrm{~h}$ period. Results (Table IV) showed that all infusions presented $\alpha$-glucosidase inhibitory activity, varying in the range $97.45-99.90 \%$ and that higher temperatures afford higher activity. After 24 hours, it was observed that there was a decrease in inhibitory activity for both GT and BT with significant differences $(p<0.001)$, even though a high hypoglycemic activity ( $>97 \%)$ was still maintained throughout the studied period, with a percentage of decreasing activity always below $0,70 \%$. These results indicate that both green and black teas are quite effective in inhibiting $\alpha$-glucosidase activity, even after a $24 \mathrm{~h}$ period.

\section{CONCLUSIONS}

The main goal of the present study was to investigate the effect of commonly used tea preparation procedures and the type of water used on possible health benefits for the consumer, evaluated by the assessment of the antioxidant and antidiabetic properties of a cup of tea.

As expected, the water temperature has some impact on RSA for both GT and BT. For GT, this effect is more significant when the temperature increases from $70^{\circ} \mathrm{C}$ to $80^{\circ} \mathrm{C}$, while for $\mathrm{BT}$, temperature has a higher impact from $80{ }^{\circ} \mathrm{C}$ to $90{ }^{\circ} \mathrm{C}$. These results are in keeping with the common temperature recommendations to obtain the best taste and aroma from a cup of tea, suggesting that GT should be prepared at $80^{\circ} \mathrm{C}$ and BT at $90^{\circ} \mathrm{C}$. From this 
TABLE IV - $\alpha$-Glucosidase inhibitory activity of green and black tea infusions

\begin{tabular}{|c|c|c|c|c|c|}
\hline \multirow{2}{*}{ Tea } & & \multirow{2}{*}{$\begin{array}{c}\text { Infusion } \\
\text { temperature }\left({ }^{\circ} \mathrm{C}\right)\end{array}$} & \multirow{2}{*}{$\begin{array}{l}\text { Infusion } \\
\text { time (min) }\end{array}$} & \multicolumn{2}{|c|}{ Inhibitory activity (\%) } \\
\hline & & & & Time: 0 h & Time: $24 \mathrm{~h}$ \\
\hline \multirow{8}{*}{ Leaves } & \multirow{4}{*}{ Green } & 70 & 3 & $99.46 \pm 0.00^{\mathrm{a}}$ & $99.00 \pm 0.01^{\mathrm{j}}$ \\
\hline & & 80 & 3 & $99.80 \pm 0.00^{\mathrm{b}}$ & $99.38 \pm 0.00^{\mathrm{k}}$ \\
\hline & & 90 & 3 & $99.90 \pm 0.00^{c}$ & $99.37 \pm 0.00^{\mathrm{k}}$ \\
\hline & & 100 & 3 & $99.89 \pm 0.00^{c}$ & $99.42 \pm 0.01^{1}$ \\
\hline & \multirow{4}{*}{ Black } & 70 & 5 & $97.45 \pm 0.00^{\mathrm{d}}$ & $97.36 \pm 0.00^{\mathrm{m}}$ \\
\hline & & 80 & 5 & $98.67 \pm 0.00^{\mathrm{e}}$ & $98.08 \pm 0.01^{\mathrm{n}}$ \\
\hline & & 90 & 5 & $99.29 \pm 0.01^{\mathrm{f}}$ & $98.85 \pm 0.00^{\circ}$ \\
\hline & & 100 & 5 & $99.60 \pm 0.00^{\mathrm{g}}$ & $99.20 \pm 0.00^{\mathrm{p}}$ \\
\hline \multirow{2}{*}{ Bags } & Green & 80 & 3 & $99.53 \pm 0.01^{\mathrm{h}}$ & $99.36 \pm 0.01^{\mathrm{m}}$ \\
\hline & Black & 90 & 5 & $99.69 \pm 0.00^{\mathrm{i}}$ & $99.66 \pm 0.01^{q}$ \\
\hline
\end{tabular}

Each uncertainty represents the standard deviation of the mean of three replicates, mean \pm SD. Different letters are indicative of significant statistical differences between the values with at least $\mathrm{p}<0.05$ (ANOVA, Tukey's test).

study, it becomes clear that these temperatures may also be recommended to obtain good antioxidant properties. When considering the type of infusion to use, tea bags originated higher TPC and RSA values than loose-leaf samples, as a consequence of a higher surface area of the tea fannings in the tea bags.

Furthermore, it was found that the $\alpha$-glucosidase inhibitory activity is very high for both BT and GT infusions. Results also show that even though this activity decreases in a 24-hours period values are still quite high (above 97\%).

Finally, this study also allowed to recognize that the water mineralization influences TPC and RSA, for both BT and GT. Results obtained when using a low mineralized commercial water were very similar to those obtained with distilled water, which has the highest TPC and RSA values. Therefore, low mineralized waters seem to be the best choice to obtain infusions with higher antioxidant activity.

\section{ACKNOWLEDGEMENTS}

This work was supported by Fundação para a Ciência e a Tecnologia (FCT), Portugal (UID/ MULTI/00612/2013).

\section{REFERENCES}

Abeywickrama KRW, Ratnasooriya WD, Amarakoon AMT. Oral hypoglycaemic, antihyperglycaemic and antidiabetic activities of Sri Lankan Broken Orange Pekoe Fannings (BOPF) grade black tea (Camellia sinensis L.) in rats. J Ethnopharmacol. 2011;135(2):278-86.
Anderson RA, Polansky MM. Tea enhances insulin activity. J Agric Food Chem. 2002;50(24):7182-6.

Baptista JAB, da P Tavares JF, Carvalho RCB. Comparative study and partial characterization of azorean green tea polyphenols. J Food Compos Anal. 1999;12(4):273-87.

Baptista JAB, Tavares JF da P, Carvalho RCB. Comparison of catechins and aromas among different green teas using HPLC/ SPME-GC. Food Res Int. 1998;31(10):729-36.

Benzie IFF, Szeto YT. Total antioxidant capacity of teas by the ferric reducing/antioxidant power assay. J Agric Food Chem. 1999;47(2):633-6.

Brand-Williams, Cuvelier ME, Berset C. Use of a free radical method to evaluate antioxidant activity. Food Sci Technol. 1995;28(1):25-30.

Caralambous G, Inglett GE. Flavor of food and beverages. London: Academic Press Inc; 1978.

Carter P. Spectrophotometric determination of serum iron at the submicrogram level with a new reagent (ferrozine). Anal Biochem. 1971;40(2):450-8.

Choi HS, Sun Song H, Ukeda H, Sawamura M. Radicalscavenging activities of citrus essential oils and their components: Detection using 1,1-diphenyl-2-picrylhydrazyl. J Agric Food Chem. 2000;48(9):4156-61. 
Emsley B. How to make a perfect cup of tea [Internet]. Royal Society of Chemistry News Release. 2003 [cited 2018 Apr 13]. Available from: https://pt.slideshare.net/cenamorado/how-tomake-a-perfect-cup-of-tea.

Gao DF, Zhang YJ, Yang CR, Chen KK, Jiang HJ. Phenolic antioxidants from green tea produced from Camellia taliensis. J Agric Food Chem. 2008;56(16):7517-21.

Gorreana. Gorreana [Internet]. 2015 [cited 2018 Apr 12]. Available from: http://gorreana.pt/en/.

Halliwell B, Gutteridge JMC. Free radicals in biology and medicine. 2nd Edition. Oxford: Clarendon Press; 1989.

Harbowy ME, Balentine DA. Tea Chemistry. CRC Crit Rev Plant Sci. 1997;16(5):415-80.

Hosoda K, Wang MF, Liao ML, Chuang CK, Iha M, Clevidence $\mathrm{B}$, et al. Antihyperglycemic effect of oolong tea in type 2 diabetes. Diabetes Care. 2003;26(6):1714-8.

Huang D, Boxin OU, Prior RL. The chemistry behind antioxidant capacity assays. J Agric Food Chem. 2005;53(6):1841-56.

Iso H, Date C, Wakai K, Fukui M, Tamakoshi A. The Relationship between Green Tea and Total Caffeine Intake. Ann Intern Med. 2016;144(8)554-62.

Koh LW, Wong LL, Loo YY, Kasapis S, Huang D. Evaluation of different teas against starch digestibility by mammalian glycosidases. J Agric Food Chem. 2010;58(1):148-54.

Komes D, Horzic D, Belscak A, Ganic KK, Vulic I. Green tea preparation and its influence on the content of bioactive compounds. Food Res Int. 2010;43(1):167-76.

Li DQ, Qian ZM, Li SP. Inhibition of three selected beverage extracts on $\alpha$-glucosidase and rapid identification of their active compounds using HPLC-DAD-MS/MS and biochemical detection. J Agric Food Chem. 2010;58(11):6608-13.

MacKenzie T, Leary L, Brooks WB. The effect of an extract of green and black tea on glucose control in adults with type 2 diabetes mellitus: double-blind randomized study. Metabolism. 2007;56(10):1340-4.
Mata AT, Proença C, Ferreira AR, Serralheiro MLM, Nogueira JMF, Araújo MEM. Antioxidant and antiacetylcholinesterase activities of five plants used as Portuguese food spices. Food Chem. 2007;103(3):778-86.

Mossion A, Potin-Gautier M, Delerue S, Le Hécho I, Behra P. Effect of water composition on aluminium, calcium and organic carbon extraction in tea infusions. Food Chem. 2008;106(4 Spec. issue):1467-75

Park J-H, Bae J-H, Im S-S, Song D-K. Green tea and type 2 diabetes. Integr Med Res. 2014;3(1):4-10.

Queiroz DPK, Ferreira AG, Lima AS, Lima ES, Lima M da P. Isolation and identification of $\alpha$-glucosidade, -amylase and lipase inhibitors from Hortia longifolia. Int J Pharmacey Pharm Sci. 2013;5(3):4-7.

Ruberto G, Baratta MT. Antioxidant activity of selected essential oil components in two lipid model systems. Food Chem. 2000;69(2):167-74.

Samaniego-Sánchez C, Inurreta-Salinas Y, Quesada-Granados JJ, Blanca-Herrera R, Villalón-Mir M, López-García de la Serrana $\mathrm{H}$, et al. The influence of domestic culinary processes on the Trolox Equivalent Antioxidant Capacity of green tea infusions. J Food Compos Anal. 2011;24(1):79-86.

Sharma V, Vijay Kumar H, Jagan Mohan Rao L. Influence of milk and sugar on antioxidant potential of black tea. Food Res Int. 2008;41(2):124-9.

Sharpe E, Hua F, Schuckers S, Andreescu S, Bradley R. Effects of brewing conditions on the antioxidant capacity of twenty.four commercial green tea varieties. Food Chem. 2016;195(4):380-7.

Singleton VL, Orthofer R, Lamuela-Raventos RM. Analysis of total phenols and other oxidation substrates and antioxidants by means of Folin-Ciocalteu reagent. Methods Enzymol. 1998;299(1974):152-78.

Received for publication on $05^{\text {th }}$ January 2018 Accepted for publication on $28^{\text {th }}$ May 2018 